\title{
Covid-19: Staff at Nightingale Hospital in London get wellbeing area courtesy of John Lewis
}

\author{
Abi Rimmer
}

The BMJ

A wellbeing area for staff and volunteers at the NHS Nightingale Hospital in east London has been created by the John Lewis Partnership. The space, within the main part of the hospital, is designed as a place where staff can take time out away from an extremely challenging workplace environment.

From 10 April the John Lewis Partnership will also be delivering care packages containing essential items for NHS staff to all acute hospital trusts in England, Wales, and Scotland. The Nightingale London and other London trusts will be the first to receive the care packages, which will be distributed to staff working in high intensity clinical areas such as critical care and intensive care units.

The packages, based on advice from the BMA, will include non-clinical essentials such as toiletries, snack food, tea, coffee, and socks. The boxes will also contain a wellbeing leaflet with information about a 24/7 counselling service and guidance from the BMA on a range of issues.
Matthew Trainer, deputy chief executive of NHS Nightingale London, said, "The care packages, designed in collaboration with the BMA, will be a welcome gesture of support for busy staff on the go, and the wellbeing space will allow our staff much needed time out during their shifts."

Chaand Nagpaul, BMA chair of council, said the BMA hoped that the boxes would bring a few smiles and some comfort to as many staff as possible.

Sharon White, partner and chair of the John Lewis Partnership, said, "We are exceptionally lucky to have an amazing health service open to all. As a small token, we're donating food and essential items to the NHS; we're making it easier for NHS workers to shop in Waitrose; and we're helping staff at the new Nightingale Hospital in London. We will do more over the coming weeks."

The John Lewis Partnership is also accommodating on-call NHS key workers on its Leckford Estate in Hampshire. 